\title{
O MINISTÉRIO PÚBLICO E O INTERESSE PÚBLICO NA PROTEÇÃO À HONRA E À DIGNIDADE DE GRUPOS RACIAIS, ÉTNICOS OU RELIGIOSOS
}

\section{IL PUBBLICO MINISTERO E L'INTERESSE PUBBLICO NELLA PROTEZIONE ALLA ONORE ED ALLA DIGNITÀ DI GRUPPI RAZZIALI, ETNICI E RELIGIOSI}

\author{
Helder Magevski De Amorim ${ }^{1}$
}

\section{RESUMO}

O presente artigo trata do Ministério Público e a existência de interesse público na proteção à honra e à dignidade de grupos raciais, étnicos e religiosos, com particular atenção na Lei n. 7.347/85 e sua posterior modificação pela Lei n. 12.966/2014. Destaca-se a importância dessa alteração legislativa em favor da luta por reconhecimento das chamadas "minorias". Mencionase também o desenvolvimento do Ministério Público para se tornar instituição voltada à proteção do interesse público. São citados ainda exemplos práticos das ações do Ministério Público em favor das minorias.

Palavras-chave: Ministério público, Interesse público, Minorias

\section{ABSTRACT}

Il testo tratta del Pubblico Ministero e l'esistenza di interesse pubblico nella protezione alla onore ed alla dignità di gruppi razziali, etnici e religiosi, con particolare attenzione nella Legge n. 7.347/85 e alla loro successiva modifica dalla Legge n. 12.966/2014. Risalta l'importanza dell'alterazione legislativa in favore della lotta per riconoscimento delle cosiddette "minoranze". É stata mencionata anche lo sviluppo del Pubblico Ministero di diventare istituzione mirata per la protezione dell'interesse pubblico. Sono citati ancora esempi pratici dell’azioni del Pubblico Ministero a favore delle minoranze.

Keywords/Palabras-claves/Mots-clés: Pubblico ministero, Interesse pubblico, Minoranze

\footnotetext{
${ }^{1}$ Mestrando em Direito pela Universidade Federal do Espírito Santo - UFES, Espírito Santo, (Brasil). Promotor de Justiça do Ministério Público do Estado do Espírito Santo, (Brasil).E-mail: hm_amorim@yahoo.com.br
} 


\section{INTRODUÇÃO}

A ação civil pública foi um instrumento criado em 1985, por meio da Lei n. 7.347, cujo objetivo naquele momento inicial era a proteção dos diretos difusos e coletivos. Posteriormente, com a Lei n. 8.069/90 - Código de Defesa do Consumidor, ampliou-se também para os direitos individuais homogêneos, conforme artigo 117 do CDC que incluiu o artigo 21 na LACP com a seguinte redação: “Aplicam-se à defesa dos direitos e interesses difusos, coletivos e individuais, no que for cabível, os dispositivos do Título III da lei que instituiu o Código de Defesa do Consumidor", Título III que trata da "Defesa do Consumidor em Juízo".

A ação civil pública exerce papel muito importante em nosso direito, pois tais processos servem, nas palavras de Didier e Zaneti, à “litigação de interesse público", posto que vão além de interesses meramente individuais para buscar proteger "aqueles referentes à preservação da harmonia e à realização dos objetivos constitucionais da sociedade e da comunidade". São interesses, como mencionam os autores, que não podem se dizer que são minoritários, porque muitas vezes dizem respeito a uma ampla maioria da sociedade, "embora não tenham voz, nem vez”. São interesses e direitos, em verdade, “marginalizados" (DIDIER JR,; ZANETI JR., 2011, v. 4, p. 37).

Serve a ação civil pública para "a defesa do interesse público primário através de litígios cíveis, inclusive na atuação de controle e realização de políticas públicas através desta “litigação”” (DIDIER JR,; ZANETI JR., 2011, v. 4, p. 37).

Nessa luta para a efetivação de direitos fundamentais, que pertencem a "minorias" que em verdade se constituem na maioria da população brasileira ${ }^{2}$, em 24 de abril de 2014, por meio da Lei n. 12.966, foram feitas alterações na Lei n. 7.347/85, passando essa ela a dispor também sobre a "proteção à honra e à dignidade de grupos raciais, étnicos ou religiosos" (artigo $1^{\circ}$, Lei n.12.966/2014).

\footnotetext{
${ }^{2}$ De acordo com o Censo de 2010, a população brasileira considerada negra e parda soma 97.171.614 (noventa e sete milhões, cento e setenta e um mil, seiscentos e quatorze) pessoas, sendo que a população total brasileira de 190.755.799 (cento e noventa milhões, setecentos e cinquenta e cinco mil, setecentos e noventa e nove) pessoas. Ou seja, a população negra e parte constitui $50,94 \%$ da população brasileira. Dados disponíveis em: <http://www.ibge.gov.br/apps/snig/v1/?loc=0\&cat=-1,-2,4,-3,128\&ind=4707>. Acesso em 18 jan. 2016.
} 
Para tanto foi inserido o inciso VII no artigo $1^{\circ}$ da LACP, de forma tal que "regem-se pelas disposições desta Lei, sem prejuízo da ação popular, as ações de responsabilidade por danos morais e patrimoniais causados: [...] à honra e à dignidade de grupos raciais, étnicos ou religiosos".

A mesma Lei n. 12.966/2014 tornou possível o ajuizamento de ação cautelar para evitar danos à honra e à dignidade de grupos raciais, étnicos ou religiosos (artigo $4^{\circ}$, Lei n. 7.347/85) e legitimou para a propositura de ação civil pública e ação cautelar as associações que incluem entre suas finalidades a proteção aos direitos de grupos raciais, étnicos ou religiosos (artigo $5^{\circ}, \mathrm{V}, b$, Lei n. 7.347/85).

Importante salientar que especificamente sobre a população negra, o artigo 55 da Lei n. 12.288/2010 - Estatuto da Igualdade Racial - já trazia expressamente a possibilidade de ajuizamento da ação civil pública nas hipóteses de lesão e de ameaças de lesão aos interesses da população negra decorrentes de situações de desigualdade étnica.

Também, a rigor, a proteção à honra e à dignidade de grupos raciais, étnicos ou religiosos já estaria amparada pela Lei da ação civil pública no artigo $1^{\circ}, \mathrm{IV}$, ao mencionar essa forma de proteção no caso de direitos difusos e coletivos.

Porém, a lei é importante porque dispensa o ônus argumentativo de enquadrar lesões e ameaças de lesões à honra e à dignidade de grupos raciais, étnicos ou religiosos como direitos difusos ou coletivos, e também porque amplia a proteção coletiva em sentido amplo para além da população negra, alcançando também toda e qualquer raça, etnia e grupos religiosos.

O Estatuto da Igualdade Racial (Lei n. 12.288/2010) traz conceitos dogmáticos acerca do que é considerado pelo direito brasileiro como uma situação de discriminação. Para os termos do mencionado Estatuto, conforme art. $1^{\circ}$, parágrafo único, inciso I, discriminação racial ou étnico-racial é

[...] toda distinção, exclusão, restrição ou preferência baseada em raça, cor, descendência ou origem nacional ou étnica que tenha por objeto anular ou restringir o reconhecimento, gozo ou exercício, em igualdade de condições, de direitos humanos e liberdades fundamentais nos campos político, econômico, social, cultural ou em qualquer outro campo da vida pública ou privada; [...]. 
Mutatis mutandis, a partir desse conceito é possível também reconhecer o que seja uma discriminação com fundamento religioso.

Qual a importância de tal modificação legislativa? Qual o fundamento para uma atuação do Ministério Público nesse tema?

O método utilizado neste artigo foi o hipotético-dedutivo, sendo feita análise investigativa, com a finalidade de que sejam empreendidas hipóteses de referência para as observações a serem feitas acerca do tema em estudo e a posterior análise da aplicação das conclusões alcançadas nos casos concretos.

\section{DA LUTA POR RECONHECIMENTO}

A luta por reconhecimento, notadamente, pelas chamadas "minorias", é uma demanda contemporânea das mais importantes. Segundo Charles Taylor a necessidade por reconhecimento

The demand for recognition in these latter cases is given urgency by the supposed links between recognition and identity, where this latter term designates something like a person's understanding of who they are, of their fundamental defining characteristics as a human being ${ }^{3}$. (TAYLOR, Charles.

Politics of Recognition. Disponível em: $<$ http://elplandehiram.org/documentos/JoustingNYC/Politics_of_Recogn ition.pdf $>$. Acesso em 20 jan. 2016).

Isso porque, na ausência dessas políticas "[...] nonrecognition or misrecognition can inflict harm, can be a form of oppression, imprisoning someone in a false, distorted, and reduced mode of being". ${ }^{4}$ (TAYLOR, loc. cit.). Um exemplo é a situação dos negros: "that white society has for generations projected a demeaning image of them, which some of them have been unable to resist adopting". 5 (TAYLOR, loc. cit.).

\footnotetext{
${ }^{3}$ A demanda por reconhecimento nesses casos recebe urgência pela existência de ligações entre reconhecimento e identidade, onde este último termo designa algo como o entendimento de uma pessoa sobre quem ela é, da definição das características fundamentais como um ser humano. (tradução nossa).

${ }^{4}$ [...] não-reconhecimento ou reconhecimento errôneo podem infligir dor, pode ser uma forma de opressão, imprisionando alguém em um modo de ser falso e distorcido. (tradução nossa).

${ }^{5}[\ldots]$ a sociedade branca por gerações projetou uma imagem degradante dos negros, que alguns não conseguiram deixar de adotar. (tradução nossa).
} 
Para Honneth, uma situação de privação de direitos e de exclusão social leva a uma perda de autorrespeito, pois são formas de desrespeito que representam a limitação violenta da autonomia pessoal e, também faz surgir o "sentimento de não possuir o status de um parceiro da interação com igual valor, moralmente em pé de igualdade” (HONNETH, 2003, p. 216) com os demais membros da sociedade.

No artigo "Guinada Semântica: indivíduo, pessoa, individualismo, individualização e sujeito de direitos fundamentais" (Cf. VINCENZI, 2009), Brunela Vieira de Vincenzi faz uma análise a partir de um julgamento do Tribunal Constitucional Alemão ocorrido em $2003^{6}$. O caso é o seguinte: uma professora de escola pública, nascida no Afeganistão, foi proibida de lecionar usando o véu durante as aulas. O fundamento para a vedação foi que a manifestação religiosa não se coadunaria com o dever de laicidade do funcionário público.

Na decisão, o Tribunal Constitucional Alemão entendeu que o caso deveria ser resolvido pelo Poder Legislativo Estadual, o qual era o competente para o caso. Isso porque a repercussão da decisão seria de tal relevância que somente os representantes do povo poderiam deliberar sobre ela.

O ponto levantado por esse caso é a importância para o indivíduo do reconhecimento de suas formas de viver. O reconhecimento é algo fundamental para a constituição da pessoa. Segundo Honneth, "para alcançar uma autorrelação bem-sucedida, ele [individuo] depende do reconhecimento intersubjetivo de suas capacidades e realizações" (apud VINCENZI, 2009, p. 105). Além disso, a pessoa tem a capacidade de efetuar o reconhecimento quando anteriormente já tiver se atribuído a capacidade de se reconhecer. É preciso se autorreconhecer para reconhecer o outro.

\footnotetext{
${ }^{6}$ Vale ressaltar que esse entendimento foi modificado em 13/03/2015: O Tribunal Constitucional Federal da Alemanha considerou nesta sexta-feira (13/03) inconstitucional qualquer norma estadual que proíba o uso de véu por parte de professoras muçulmanas nas escolas do país. Revertendo uma decisão de 2003, que permitia aos estados legislarem sobre o tema, os juízes do tribunal com sede em Karlsruhe agora decidiram que eventuais "riscos abstratos" à ordem escolar e à neutralidade não justificam a proibição, e que esta ameaça a liberdade religiosa no país. Portanto, sem um risco concreto, não se deve proibir o uso do véu islâmico ou de qualquer outra peça do vestuário, masculina ou feminina, ligada a uma determinada religião. Disponível em: http://www.dw.com/pt/alemanha-anula-proibi\%C3\%A7\%C3\%A3o-de-v\%C3\%A9u-isl\%C3\%A2mico-paraprofessoras/a-18314534. Acesso em 24 de nov. 2015.
} 
Salienta Fuhrmann que "o não reconhecimento é uma herança transgeracional, particularmente, das classes populares e dos segmentos marginalizados moralmente" (Cf. FUHRMANN, 2013).

Imprescindível, assim, uma atuação do direito em prol do reconhecimento de pessoas e de grupos de pessoas, notadamente aqueles que são deixados de lado, as ditas "minorias", para se quebrar essa "herança maldita" de exclusão nos seus mais variados modos.

Percebe-se a importância dos direitos fundamentais como essenciais para que o indivíduo possa refletir e tomar as suas próprias decisões, defina seu próprio destino, possa determinar a sua própria liberdade. Possui papel relevante nisso os direitos à dignidade de grupos raciais, étnicos ou religiosos.

A função dos direitos fundamentais pode ser especificada nesse caso como a de é permitir que o indivíduo possa refletir sobre os seus direitos e definir por si a sua liberdade. Com isso, ele poderá entender o seu papel na sociedade, lutando pelo reconhecimento devido, a partir também de sua cultura, de sua forma de viver, a qual deve ser protegida.

Importante, portanto, a criação de instrumentos processuais para a defesa desses direitos, tal qual feito pela Lei n. 12.966/2014.

A partir dessa explanação fica evidente a existência de um interesse público na atuação do Poder Público para a proteção à honra e à dignidade de grupos raciais, étnicos ou religiosos. É, portanto, um campo em que se faz necessária a intervenção do Ministério Público.

\section{O MiNistério PÚBLICO E SUA EVOLUÇÃo INSTITUCIONAL PARA A INSTITUIÇÃO DE PROTEÇÃO DO INTERESSE PÚBLICO}

Nos termos do artigo 127 da Constituição de 1988, o Ministério Público

[...] é instituição permanente, essencial à função jurisdicional do Estado, incumbindo-lhe a defesa da ordem jurídica, do regime democrático e dos interesses sociais e individuais indisponíveis.

Esse dispositivo da Constituição de 1988 é um ápice das lutas realizadas ao longo de anos para que o Ministério Público brasileiro tivesse essa modelagem de instituição que represente os interesses da sociedade e o respeito aos direitos fundamentais. 
Na Constituição de 1824 não existe nenhuma menção ao Ministério Público. O primeiro texto legal a “dedicar tratamento sistemático e abrangente à Instituição do Ministério Público" (MACHADO, 1998, p. 17) foi o Código de Processo Criminal de 1832 (Lei de 29 de Novembro de 1932). Nele estão previstos a forma de escolha dos "Promotores Públicos", as suas atribuições e hipótese de substituição em caso de impedimento.

Com o advento da República, especificamente até a Emenda Constitucional n. 1/1969, a história do Ministério Público é caracterizada por avanços em determinados momentos, seguidos por retrocessos logo em seguida.

A Constituição de 1891 somente fez referência ao Procurador-Geral da República dentro do título do Poder Judiciário, indicando que ele seria escolhido dentre os Ministros do Supremo Tribunal Federal.

A Constituição de 1934 representou avanço. O Ministério Público não estava inserido em nenhum poder, figurando inclusive em capítulo autônomo (Capítulo VI: Dos Órgãos de Cooperação nas Atividades Governamentais).

O Ministério Público experimentou grande retrocesso com a Constituição de 1937, decretada por Getúlio Vargas em 10 de novembro de 1937. Nela, há menção do Parquet em apenas dois dispositivos - artigos 99 e 105, os quais tratam do Procurador-Geral da República - "que funcionará junto ao Supremo Tribunal Federal, e será de livre nomeação e demissão do Presidente da República, devendo recair a escolha em pessoa que reúna os requisitos exigidos para Ministro do Supremo Tribunal Federal" - e do quinto constitucional nos Tribunais Superiores, que deveria ser formado por membros do Parquet.

Nesse movimento de idas e vindas, a Constituição de 1946 representou um progresso. O Ministério Público voltou a contar com previsão em título próprio (Título III - artigos 125 a 128), o Procurador-Geral da República seria nomeado pelo Presidente da República, após aprovação e escolha pelo Senado - podendo, porém, ser demissível ad nutum -, ingresso na carreira por meio de concurso público e estabilidade para os membros após dois anos de exercício.

Com as Constituições de 1967 e 1969 o Ministério Público experimentou novas involuções. Na de 1967 passou a ser inserido no Poder Judiciário, o que durou pouco, vez que 
na Constituição de 1969 foi colocado no âmbito do Poder Executivo, além de ter expurgadas conquistas anteriores: perda das "mesmas condições de aposentadoria e vencimentos atribuídos aos juízes" (MACHADO, 1998, p. 17) e perda de sua independência, vez que subordinado ao Executivo. O membro do Ministério Público tinha direito à inamovibilidade, mas não à vitaliciedade (somente para os componentes do Poder Judiciário) e a irredutibilidade de vencimentos não estava prevista na Constituição, e sim apenas em leis infraconstitucionais (Cf. LIMA, 1998).

No campo constitucional, a partir da Emenda Constitucional n. 7, de 1977, inicia-se um novo movimento de fortalecimento do Ministério Público. O artigo 96 da Constituição de 1969 ganha nova redação, consignando que o Ministério Público dos Estados será organizado em carreira, por lei estadual, e no mesmo artigo foi inserido um parágrafo único, determinando que lei complementar de iniciativa do Presidente da República estabelecesse normas gerais para a organização dos Ministérios Públicos Estaduais, atentando-se ao já disposto no artigo 95, §1º, que trazia diretivas para o Ministério Público da União.

A Emenda n. 7, de 1977, foi um dos pontos chaves na evolução do Ministério Público, pois a partir dela foi possível a criação de um estatuto básico comum para a instituição, o que até então não existia.

Como decorrência da mencionada emenda constitucional surgiu a Lei Complementar n. 40, a qual entrou em vigor em 14 de dezembro de 1981. Seus três primeiros artigos são os antepassados diretos do que posteriormente viria a ser consagrado na Constituição de 1988.

No seu artigo $1^{\circ}$, a Lei Complementar n. 40/81 coloca que o Ministério Público

[...] instituição permanente e essencial à função jurisdicional do Estado, é responsável, perante o Judiciário, pela defesa da ordem jurídica e dos interesses indisponíveis da sociedade, pela fiel observância da Constituição e das leis, e será organizado, nos Estados, de acordo com as normas gerais desta Lei Complementar.

É evidente a semelhança com o texto do artigo 127 da Constituição de 1988. Salvo algumas diferenças de redação, o núcleo de sentido presente no artigo $1^{\circ}$ da Lei Complementar n. 40/81 já dizia bastante sobre os caminhos que seriam adotados pelo Ministério Público. 
Pela primeira vez na história do Ministério Público brasileiro são previstos os princípios institucionais da unidade, indivisibilidade e da autonomia funcional, conforme previsto no artigo $2^{\circ}$ da aludida lei complementar.

No artigo $3^{\circ}$ foram elencadas três funções institucionais:

Art. $3^{\circ}$ - São funções institucionais do Ministério Público: velar pela observância da Constituição e das leis, e promover-lhes a execução; promover a ação penal pública; promover a ação civil pública, nos termos da lei.

Esses avanços se consagraram com a Constituição de 1988. O Ministério Público atingiu um patamar nunca antes visto na história do país. Ele agora não está vinculado a nenhum dos três tradicionais poderes. É órgão independente e permanente, exercendo função essencial à justiça, cabendo-lhe a defesa da ordem jurídica, do regime democrático e dos interesses sociais e individuais indisponíveis (artigo 127, caput). É regido por três princípios institucionais: unidade, indivisibilidade e independência funcional (artigo 127, $\S 1^{\circ}$ ).

No âmbito administrativo, possui autonomia funcional e administrativa (artigo 127, $\S 2^{\circ}$ ) e poder para elaborar sua proposta orçamentária (artigo $127 . \S^{\circ}$ ).

No artigo 129 a Constituição elencou de forma não definitiva (“exercer outras funções que lhe forem conferidas, desde que compatíveis com sua finalidade") uma série de funções institucionais do Ministério Público: promover, privativamente a ação penal pública; zelar pelo respeito aos direitos assegurados na Constituição por parte dos Poderes Públicos e serviços de relevância pública, promovendo medidas necessárias a garantia desses direitos; promover ação de inconstitucionalidade e representação para intervenção na União e Estados; defender os direitos das populações indígenas; expedir notificações nos procedimentos administrativos que tenha instaurado, com o poder de requisitar informações e documentos; exercer o controle externo da atividade policial; requisitar a instauração de inquérito policial e de diligências investigatórias.

Há também uma importante vedação, prevista no artigo 129, IX, que contribui para marcar a independência do Ministério Público e o seu papel de fiscalizador dos Poderes Públicos: a proibição de exercer a representação judicial e a consultoria de entidades públicas.

Percebe-se que o regramento atual em nível constitucional do Ministério Público é bem superior ao presente em qualquer outra constituição brasileira. A Constituição de 1988 
trouxe em minúcias uma série de funções e vedações ao Ministério Público que o colocam na vanguarda mundial.

Interessante se notar, a partir dessa perspectiva histórica brasileira, que nos momentos de fortalecimento da democracia o Ministério Público é uma instituição que é robustecida. Contudo, quando se pretendeu diminuir o âmbito de alcance democrático se diminui também o Ministério Público.

Portanto, quanto mais democrático o momento histórico brasileiro maiores os poderes do Ministério Público. Quando se quis mitigar a democracia, retiram-se poderes do Ministério Público. As Constituições brasileiras de 1934, 1946 e 1988, tidas como de caráter democrático, foram as que mais avançaram em relação ao Ministério Público, atentando-se, por óbvio, aos seus respectivos momentos históricos.

\section{O MINISTÉRIO PÚBLICO E O INTERESSE PÚBLICO}

No artigo 127, caput, da Constituição, ao Ministério Público é atribuída a defesa da ordem jurídica, do regime democrático e dos interesses sociais e individuais indisponíveis.

As Constituições de 1934 e 1946, tidas até então como mais "avançadas" em relação ao tratamento do Ministério Público, não vão além de delinear questões administrativas da instituição, como forma de organização, modos de ocupação dos cargos, garantias dos membros.

Já os diplomas processuais civis anteriores ao Código de Processo Civil de 1973 limitam a atuação do Ministério Público a casos individuais, processos com a presença de menores ou pessoas incapazes, ou em que são discutidos direitos de família.

Não obstante reconhecermos que no início do CPC/73 o Ministério Público era uma instituição que "ainda se encontrava voltada à burocrática intervenção em feitos de cunho individual iniciados por terceiros ou mesmo à posição de autor na área penal" (BERCLAZ; MOURA, 2016, p. 458), um marco a partir do qual o Ministério Público brasileiro acabou se distinguindo em relação ao de outros países, e que foi importante para posteriormente serem alcançados os avanços percebidos a partir da Emenda Constitucional n. 7, de 1977, e que resultaram na Constituição de 1988, está no artigo 82, III, do Código de Processo Civil de 1973: 
a necessidade de intervenção nas causas em que há interesse público evidenciado pela natureza da lide ou qualidade da parte.

Reconhecemos a dificuldade em se encontrar uma definição de interesse público, a ponto de J. J. Calmon de Passos defender que

[...] a relatividade, pois, da expressão interesse público é evidente. [...] Ela deve ser usada sem que se lhe reconheça um significado ao qual corresponda, diretamente, qualquer coisa de real, mas com o fito exclusivo de indicar, mediatamente, os interesses públicos concretos ou algum dentre eles (PASSOS, 1979, p. 96).

Igualmente Mancuso, acerca da tentativa de diferenciação entre interesse social, geral e público, para quem "mesmo que seja possível [...] surpreender certos elementos identificadores de cada espécie, eles não são em número e intensidade que permita a autonomia conceitual dessas expressões entre si”, entendendo que podem ser tratadas como sinônimas sem maiores inconvenientes (MANCUSO, 2013, p. 41).

No entanto, é necessário buscarmos contornos para diminuir a vaguidade desse termo ${ }^{7}$. Apesar de a expressão "interesse público" estar inserida no ponto que diz respeito à atuação do Ministério Público como órgão interventor, tanto no Código de Processo Civil de 1973, quanto no Código de Processo Civil de 2015, entendemos que ela é um guia para o entendimento que o trabalho do Parquet independente de forma de atuação, independente se é órgão interveniente ou agente. Nesses dois papéis, o Ministério é parte. E como parte, deve sempre zelar pelo interesse público.

Em que consiste esse interesse público? Essa expressão é mencionada no artigo 82, III, do Código de Processo Civil de 1973 e no Código de Processo Civil de 2015 está no artigo 178, I, como "interesse público ou social”.

Entendemos, tendo em vista a superioridade hierárquica da Constituição, que o interesse público ao qual cabe o Ministério Público zelar deve ser interpretado a partir do disposto no artigo 127, caput, da Constituição, que determina ao Ministério Público o zelo pela "ordem jurídica, o regime democrático e os interesses sociais e individuais indisponíveis".

\footnotetext{
7 Para Tárek Moysés Moussallen, a vaguidade "é o estado de indeterminação da palavra, é sua condição de imprecisão”. In MOUSSALLEN, Tárek Moysés. Fontes do Direito Tributário. São Paulo: Max Limonad. 2006. p. 55.
} 
Pensamos que a classificação de Renato Alessi acerca do interesse público é uma chave para se definir quais são esses direitos a que cabe a tutela pelo Ministério Público. Para ele

[...] o interesse público primário (bem geral) pode ser identificado como o interesse social, o interesse da sociedade ou da coletividade, e mesmo com os mais autênticos interesses difusos (o exemplo, por excelência, do meio ambiente em geral) (ALESSI, 1960, apud MAZZILLI, 2013, p. 119).

Em sentido semelhante, para Vicente Greco Filho, esse interesse público que enseja a intervenção do Ministério Público "existiria apenas quando estivesse em jogo algum bem social indisponível transcendente, isto é, acima dos interesses individualizados das partes" (GRECO FILHO, 2009, p. 172).

E completa:

Essa última posição é adequada à própria natureza do Ministério Público, cuja legitimidade para intervir está fundamentada num interesse social indisponível. Assim, parece-nos que, fora dos casos expressos em lei, o Ministério Público deverá intervir apenas quando surgir algum interesse de ordem pública, isto é, concernente aos interesses básicos e fundamentais da sociedade (GRECO FILHO, loc. cit.).

Mazzilli parte da definição de Alessi e vai além. Ao tratar do "zelo das principais formas de interesse público", ele diz que a "defesa da ordem jurídica, do regime democrático e dos interesses sociais e individuais indisponíveis", em última análise, representam o "zelo pelo interesse público" (MAZZILLI, 2013, p. 118). Ou seja, há interesse público primário quando está em jogo a ordem jurídica, o regime democrático e interesses sociais e individuais indisponíveis.

O zelo pela ordem jurídica, pelo regime democrático e pelos interesses sociais possuem uma clara ligação com o que seja "bem geral" na definição de interesse público primário proposta por Alessi. Mazzilli defende que nesse gênero "interesse público primário" também pode se identificar com direitos individuais indisponíveis:

Num sentido mais amplo, portanto, até o interesse individual, se indisponível, é interesse público, cujo zelo é cometido ao Ministério Público; a defesa do próprio interesse coletivo, considerado em sentido lato (aquele que reúne uma categoria determinada ou pelo menos determinável de indivíduos), também pode coincidir com o zelo do interesse público empreendido pela instituição (Ibidem, p. 119-120). 
Essa ampliação de entendimento do que seja interesse público primário para abarcar a ordem jurídica, regime democrático e os interesses sociais e individuais indisponíveis, ou seja, bens sociais de indisponibilidade transcendente, encontra guarida na estreita relação deles com o que sejam direitos fundamentais.

Daniel Sarmento defende uma visão dos direitos fundamentais dentro de uma dimensão objetiva, “que se liga à compreensão de que eles não só conferem aos particulares direitos subjetivos - a tradicional dimensão subjetiva -, mas constituem também as próprias "bases jurídicas da ordem jurídica da coletividade" (SARMENTO, 2007, p. 82).

Continua Sarmento explicando que os direitos fundamentais protegem os bens jurídicos mais valiosos de uma sociedade, sendo dever do Estado não somente deixar de violar esses direitos, mas também adotar medidas para promovê-los e evitar que terceiros os violem. A garantia dos direitos fundamentais "torna-se também um autêntico interesse público" (Ibidem, p. 82-83).

Se levado às últimas consequências essa equiparação entre interesse público primário e direitos fundamentais, o Ministério Público seria obrigado a intervir em todo e qualquer tipo de ação, mesmo entre pessoas maiores e capazes e litigando sobre direitos estritamente patrimoniais, afinal, por exemplo, a propriedade é um direito fundamental, tal qual o direito de ação. Não pode ser essa a interpretação, sob pena de uma interferência indevida em situações em que o indivíduo pode se autodeterminar.

Pensamos que a atuação do Ministério Público, como órgão agente ou interveniente, deve ocorrer nos casos em que presente interesse público primário, o qual deve ter por característica a indisponibilidade.

Conforme Justen Filho um interesse é público “por ser indisponível, e não o inverso. [...]. O interesse é reconhecido como público porque é indisponível, porque não pode ser colocado em risco, porque sua natureza exige que seja realizado" (JUSTEN FILHO, 2014, p. 158-159).

Em sentido semelhante, Machado diz que o artigo 127, caput, da Constituição deve ser interpretado no sentido de que cabe ao Ministério Público 
[...] a defesa da ordem jurídica amplamente considerada (a defesa da Constituição Federal e das leis substanciais e instrumentais) nos processos em que os litígios envolvam leis de ordem pública, quer dizer, as que criam direitos indisponíveis. O que torna possível e legítima a atuação tutelatória do Ministério Público é, portanto, a indisponibilidade de direitos que resulta da existência de leis de ordem pública [...] (MACHADO, 1998, p. 45-46).

Mais uma vez, o que enseja a atuação do Ministério Público é lesão ou ameaça a lesão de um direito social ou individual indisponível. Necessariamente cabe ao Ministério Público intervir em favor da ordem jurídica e do regime democrático quando estiver envolvido um direito social indisponível ou individual indisponível. Em outras palavras, a defesa da ordem jurídica e do regime democrático para determinar a intervenção do Parquet deve estar conjugada com um direito indisponível - seja social ou individual.

\section{O MiNistério PÚblico e A PROTEÇÃo À HONRA E À DIGNIDAdE DE GRUPOS RACIAIS, ÉTNICOS OU RELIGIOSOS - EXEMPLOS DE ATUAÇÃO}

No livro "Democracia através dos direitos", Luigi Ferrajoli defende um “constitucionalismo garantista". Ferrajoli define o garantismo como a

[...] sujeição ao direito de quaisquer poderes, sejam eles públicos ou privados, por intermédio de regras, vínculos e controles jurídicos idôneos a impedir o exercício arbitrário ou ilegal destes próprios poderes, com vistas à garantia dos direitos de todos (FERRAJOLI, 2015, p. 31).

Em outras palavras, o garantismo é o "o conjunto dos limites e dos vínculos impostos a quaisquer poderes, idôneos a garantir a máxima efetividade de todos os direitos e de todas as promessas constitucionais" (FERRAJOLI, loc. cit.).

Com base nisso, Ferrajoli construiu o "constitucionalismo garantista”. Ele se configura “no plano teórico, como uma complementação, seja do positivismo jurídico [...] seja do Estado de direito e da democracia" e tem como principais características a de determinar o respeito à Constituição

[...] na medida em que comporta submissão de todos os poderes, inclusive o político e o legislativo, a normas formais e substanciais destinadas, primeiramente, a limitar-lhes e a vincular-lhes o exercício e, de maneira secundária, a censurar ou a remover as violações que venham a cometer para a garantia dos direitos de todos (Ibidem, p. 12). 
Segundo Ferrajoli, a fim de cumprir os objetivos a que se propõe o constitucionalismo garantista, ele é calcado em quatro postulados: o princípio da legalidade ${ }^{8}$, princípio da completude deôntica ${ }^{9}$, princípio da jurisdicionalidade ${ }^{10}$ e o princípio da acionabilidade.

Especificamente sobre o princípio da acionabilidade, tal pode ser definido como a possibilidade de ativar a jurisdição. Com base nele

[...] onde quer que exista uma jurisdição deve igualmente ser prevista, como ulterior garantia secundária, a sua ativação por parte dos titulares dos direitos e dos interesses lesados e, de modo complementar e subsidiário, por parte de um órgão público em condições de suprir a possível inércia ou hipossuficiência daqueles (Ibidem, p. 65).

Em síntese, é o exercício do direito de ação (Ibidem, p. 244). Contudo, de acordo com Ferrajoli, o acesso à justiça por meio de ações individuais nem sempre é o suficiente para proteção de direitos sociais.

Assim, para fazer a defesa desses direitos, por meio do princípio da acionabilidade, entram em jogo as chamadas instituições de garantia. Uma delas é a Defensoria Pública. A outra - e ainda mais importante, consoante o autor - é o Ministério Público.

Deve haver um "Ministério Público em Berlim" a fim de "manejar ações para a tutela dos direitos fundamentais e, em particular, dos direitos sociais, bem como dos interesses públicos e dos bens constitucionais violados pelos poderes públicos” (Ibidem, p. 246-247).

Para Ferrajoli, o Ministério Público possui a obrigação de garantir a efetividade dos direitos, visto que os direitos fundamentais são a "lei dos mais fracos" (Ibidem, p. 247), a lei de proteção daqueles que estão em situação de vulnerabilidade.

\footnotetext{
8 "Com base nele, onde quer que haja um poder, seja ele público ou privado, executivo, judiciário ou legislativo, estatal, extraestatal ou supra-estatal, devem existir normas primárias, não apenas formais, mas também substanciais, que regulem o seu exercício, submetendo-o aos limites e aos vínculos nos quais consistem as garantias primárias correspondentes aos direitos e aos interesses constitucionalmente estabelecidos, bem como à separação entre os poderes que impedem as confusões ou concentrações destes”. (Ibidem, p. 62-63).

9 “O segundo postulado é o princípio da completude deôntica, por força do qual, onde quer que existam direitos ou interesses estabelecidos por normas primárias, devem ser introduzidos, como garantias primárias deles, os deveres correspondentes, isto é, a proibição de lesá-los e a obrigação de tutelá-los e de satisfazê-los, por parte das funções e instituições de garantias primárias, por sua vez separadas de qualquer outro poder”. (Ibidem, p. 63-64).

10 "O terceiro postulado é o princípio de jurisdicionalidade, o qual impõe que onde quer que existam normas e garantias primárias, também devem existir, contra as suas possíveis violações, normas secundárias, que predisponham a intervenção de garantias secundárias ou jurisdicionais levadas a efeito por funções e instituições de garantia, por sua vez secundárias, também estas separadas de qualquer outro poder”. (Ibidem, p. 65).
} 
Como já mencionado, o Ministério Público é instituição vocacionada constitucionalmente à proteção do interesse público primário, ou seja, dos direitos sociais e individuais indisponíveis. Muito mais ainda quando for o caso de uma proteção de natureza transindividual.

É inegável que existe interesse público primário na proteção da honra e dignidade de grupos raciais, étnicos ou religiosos. As disposições sobre o tema no texto constitucional são um exemplo claro disso.

A Constituição de 1988 estabelece que a República Federativa do Brasil tem como um de seus fundamentos a dignidade da pessoa humana (art. $1^{\circ}$, III). Constitui um dos objetivos fundamentais da República a promoção do bem de todos, "sem preconceitos de origem, raça, sexo, cor, idade e quaisquer outras formas de discriminação" (art. $3^{\circ}$, IV).

No artigo $5^{\circ}$ está garantida a inviolabilidade da liberdade de crença, sendo assegurado o livre exercício de cultos religiosos e garantida a proteção aos locais de culto e a suas liturgias (inciso VI), é prevista a assistência religiosa nas entidades civis e militares de internação coletiva (inciso VII), ninguém será privado de direitos por motivo de crença religiosa (inciso VIII), o racismo é considerado crime inafiançável e imprescritível (inciso XLII).

A Constituição dedica todo um capítulo em atenção dos indígenas (artigos 231 e 232). O trabalho do Ministério Público em prol dos povos indígenas é expresso na Constituição, sendo uma de suas funções institucionais "defender judicialmente os direitos e interesses das populações indígenas" (art. 129, V) e sua intervenção é obrigatória nas ações ajuizadas pelos índios, suas comunidades e organizações em defesa de seus direitos e interesses (art. 232).

Em caso de violação a esses direitos, o Ministério Público, como instituição de garantia de direitos indisponíveis, deve fazer uso dos seus instrumentos legais, dentre eles a ação civil pública, nos termos do princípio da acionabilidade de Ferrajoli.

Vários são os exemplos de ações ajuizadas pelo Ministério Público em amparo aos direitos indicados no artigo $1^{\circ}$, VII, da Lei n. 7.347/85, mesmo antes da inclusão desse inciso pela Lei n. 12.966/2014, e que demonstram como a instituição vem atuando em seu papel de instituição de garantia. 
Em agosto de 2014 o Ministério Público Federal em São Paulo ajuizou ação civil pública contra a Editora Abril, responsável pela Revista Veja, em razão de reportagem publicada em 05 de maio de 2010 na qual criticava de forma abusiva e discriminatória as populações indígenas e quilombolas ao tratar de demarcação de reservas em prol desses $\operatorname{grupos}^{11}$.

Em julho de 2015 o Ministério Público Federal no Distrito Federal propôs ação civil pública para que a União seja obrigada a reservar para negros e pardos $20 \%$ das vagas para admissão na Escola Preparatória de Cadetes do Exército (EsPCEx) $)^{12}$.

Destaque-se também ação civil pública impetrada pelo Ministério Público do Estado da Bahia e pelo Ministério Público Federal no Estado da Bahia contra empresário que realizou loteamento clandestino e para tanto destruiu construções tidas como sagradas e uma área verde do terreiro "Zô Ogodô Malê Bogum Seja Hundê - Roça do Ventura"

Outro exemplo é o termo de compromisso socioambiental (a rigor, um termo de ajustamento de conduta, com previsão no artigo $5^{\circ}, \S 6^{\circ}$, da Lei n. $\left.7.347 / 85\right)$ firmado entre o Ministério Público Federal no Espírito Santo e a Vale S/A em junho de 2014, para que a empresa aplique $\mathrm{R} \$ 5.000 .000,00$ (cinco milhões de reais) em projetos que levem benefícios às comunidades indígenas de Aracruz/ES, atingidas pela construção de uma estrada de ferro ${ }^{14}$.

\footnotetext{
11 "O texto da Veja procurou caracterizar a criação de novas reservas como fruto do conchavo entre ativistas que sobreviveriam dos sucessos das demarcações, agentes públicos e antropólogos cujo trabalho não teria nenhum rigor científico, mas simplesmente viés ideológico de esquerda. A revista relata ter descoberto "uma verdadeira fauna de espertalhões" e utiliza vários termos depreciativos que incitam o preconceito contra as comunidades indígenas e outras minorias étnicas. Exemplo é a definição de Tupinambás como "os novos canibais", associando-os a invasões, saques e outras práticas delituosas". Disponível em: <http://www.prsp.mpf.mp.br/sala- deimprensa/noticias_prsp/29-08-14-mpf-pede-que-editora-abril-seja-condenada-a-pagar-r-1-milhao-de-

indenizacao-por-reportagem-discriminatoria-contra-minorias-etnicas/?searchterm=ind $\% \mathrm{C} 3 \% \mathrm{ADgenas}>$. Acesso em 19 jan. 2016.
}

12 Disponível em:<http://noticias.pgr.mpf.mp.br/noticias/noticias-do-site/fiscalizacao-de-atosadministrativos/mpf-df-quer-garantir-reserva-de-vagas-para-negros-e-pardos-em-concursos-das-forcas-armada. Acesso em 19 jan. 2016.

${ }^{13}$ Disponível em: <http://www.mpba.mp.br/noticia/26872>. Acesso em 19 jan. 2016. 


\section{CONCLUSÃO}

Este artigo tratou do Ministério Público e o interesse público na proteção à honra e à dignidade de grupos raciais, étnicos e religiosos. Mencionou-se a importância da Lei n. 7.347/85 - Lei da Ação Civil Pública - para a efetivação dos direitos transindividuais, servindo tais ações como "litigação de interesse público" para a proteção dos objetivos constitucionais e anseios maiores da sociedade.

Grande avanço em prol desses direitos foi obtido com a Lei n. 12.966, de 24 de abril de 2014, a qual trouxe alterações na Lei n. 7.347/85, tornando expressa a possibilidade de proteção por meio de ação civil pública da honra e da dignidade de grupos raciais, étnicos ou religiosos. Defendeu-se que a lei é importante porque, dentre outros motivos, dispensa a necessidade de argumentar que tais direitos são difusos ou coletivos.

Essa lei vem empreendida no bojo das lutas por reconhecimento realizadas a longos tempos pelas "minorias". Passou-se importância que o reconhecimento da pessoa possui para o desenvolvimento pessoal e de seu grupo.

Em seguida passamos a tratar do Ministério Público e a sua evolução institucional para se tornar um dos órgãos estatais para a proteção dos direitos fundamentais. Traçou-se um breve histórico acerca do seu tratamento constitucional ao longo da história, culminando com a Constituição de 1988, a qual trouxe avanços únicos para a instituição, incumbindo-a de zelar pela ordem jurídica, pelo regime democrático e pelos interesses sociais e individuais indisponíveis.

Lembrou-se que esse patamar alcançado pelo Ministério Público teve como um dos momentos cruciais o disposto no artigo 82, III, do Código de Processo Civil de 1973, o qual coloca como obrigação do Parquet intervir nas causas em que há presença de interesse público.

Diante da vaguidade do termo, procuramos identificar o interesse público ao qual cabe ao Ministério Público zelar como o interesse público primário de Alessi e a contribuição para esse conceito de Mazzilli, que identifica o interesse público primário como a defesa da ordem

\footnotetext{
14 Disponível em: < http://www.pres.mpf.mp.br/site/noticias/ler_noticia.zul?noticia=1979\&categoria=0 >. Acesso em 19 jan. 2016.
} 
jurídica, do regime democrático e dos interesses sociais e individuais indisponíveis com o próprio interesse público primário.

Lembramos ainda que se esse entendimento, a rigor, determinaria a intervenção do Ministério Público em todo e qualquer processo judicial. Assim, defendemos que a atuação do Ministério Público deve ser marcada pelos casos em que esteja presente situação de indisponibilidade, levando à nossa conclusão que a proteção dos interesses públicos primários envolve a proteção dos direitos marcados por uma indisponibilidade social ou individual.

Sustentamos que há interesse público primário na proteção da honra e dignidade de grupos raciais, étnicos ou religiosos, diante, por exemplo, da forma como esse tema é tratado ao longo do texto constitucional e trouxemos exemplos de como o Ministério Público vem efetivando em casos concretos a defesa desses direitos.

\section{REFERÊNCIAS}

BERCLAZ, Márcio Soares; MOURA, Millen Castro Medeiros de. O Ministério Público e o processo coletivo no novo Código de Processo Civil. In ZANETI JR, Hermes. Processo Coletivo. Salvador: Juspodivm, 2016.

DIDIER JR., Fredie; ZANETI JR. Curso de Direito Processual Civil. Vol. 4. 6 ed. Salvador: Juspodivm, 2011.

FERRAJOLI, Luigi. A Democracia através dos direitos: o constitucionalismo garantista como modelo teórico e projeto político. Trad. Alexander Araujo de Souza e outros. São Paulo: Editora Revista dos Tribunais, 2015.

FUHRMANN, Nadia. Luta por reconhecimento: reflexões sobre a teoria de Axel Honneth e as origens dos conflitos sociais. Barbarói. Santa Cruz do Sul, n. 38. p. 79-96, jan./jun. 2013.

GRECO FILHO, Vicente. Direito processual civil brasileiro. Vol 1. 21 ed. São Paulo: Saraiva, 2009.

HONNETH, Axel. Luta por reconhecimento: a gramática moral dos conflitos sociais. São Paulo: Ed. 34, 2003. 
JUSTEN FILHO, Marçal. Curso de Direito Administrativo. 10 ed. São Paulo: Editora Revista dos Tribunais, 2014.

LIMA, Alcides de Mendonça. Atividade do Ministério Público no Processo Civil. Revista de Processo. Vol. 10. Abr. 1978.

MACHADO, Antônio Cláudio da Costa. A intervenção do Ministério Público no processo civil brasileiro. 2 ed. São Paulo: Saraiva, 1998.

MANCUSO, Rodolfo de Camargo. Interesses difusos. 8 ed. São Paulo: Editora Revista dos Tribunais, 2013.

MAZZILlI, Hugo Nigro. Regime Jurídico do Ministério Público: análise do Ministério Público na Constituição, na Lei Orgânica Nacional do Ministério Público, na Lei Orgânica do Ministério Público da União e na Lei Orgânica do Ministério Público paulista. 7 ed. São Paulo: Saraiva. 2013.

MOUSSALLEN, Tárek Moysés. Fontes do Direito Tributário. São Paulo: Max Limonad. 2006.

PASSOS, J. J. Calmon de. Intervenção do Ministério Público nas causas a que se refere o artigo 82, III, do Código de Processo Civil. Revista Justitia. São Paulo, 41 (107): 80-101, out./dez. 1979.

SARMENTO, Daniel. Interesses Públicos vs. Interesses privados na perspectiva da teoria e da filosofia constitucional. In SARMENTO, Daniel. Org. Interesses públicos versus interesses privados: desconstruindo o princípio de supremacia do interesse público. $2^{\mathrm{a}}$ Tiragem. Lumen Juris: Rio de Janeiro, 2007.

TAYLOR, Charles. Politics of Recognition. Disponível em: < http://elplandehiram.org/documentos/JoustingNYC/Politics_of_Recognition.pdf>. Acesso em 20 jan. 2016.

VINCENZI, Brunela Vieira de. Guinada Semântica: Indivíduo, Pessoa, Individualizacao e Sujeito de Direitos Fundamentais. In: CARLINI, Angélica Luciá; NALINI, José Renato. (Org.). Formação Jurídica e Direitos Humanos. Rio de Janeiro: Forense, 2009. p. 99-116. 